J. Clin. Chem. Clin. Biochem.

Vol. 22, 1984, pp. 1-13

\title{
Comparative Studies on the Oxidative Processes During Phagocytosis Measured by Luminol-Dependent Chemiluminescence
}

\author{
By G. Bruchelt and K. H. Schmidt \\ Chirurgische Klinik, Universität Tübingen
}

(Received April 25/August 15, 1983)

Summary: Four different methods, using luminol-enhanced chemiluminescence, are described for assessment of the oxidative processes associated with the phagocytosis of opsonized zymosan by granulocytes. The techniques described in the literature using whole blood as a substrate gave unreliable results due to quench effects of contaminating red blood cells, unpredictable serum interferences, or varying ratios of granulocytes and zymosan. In order to avoid these side effects, rapid and simple methods for the isolation of the granulocytes were applied, e.g. lysis of erythrocytes by ammonium chloride, or the isolation of granulocytes on a percoll gradient. The latter procedure proved to be reliable, simple and sufficiently quick for a routine application.

Vergleichende Untersuchungen von oxidativen Prozessen während der Phagocytose mittels Luminol-abhängiger Chemilumineszenz

Zusammenfassung: In der vorliegenden Arbeit werden vier verschiedene Methoden zur Messung der oxidativen Prozesse während der Phagocytose von Granulocyten unter Verwendung der Luminol-verstärkten Chemilumineszenz beschrieben. Da mit den in der Literatur für Vollblut beschriebenen Verfahren wegen Quencheffekten durch Erythrocyten, unspezifischer Serumeffekte oder variabler Verhältnisse von Granulocyten zu aufzunehmenden Partikeln keine befriedigenden Ergebnisse erhalten wurden, wurden schnelle und einfache Verfahren der Isolierung von Granulocyten angewandt. Zum einen wurden die Erythrocyten im Vollblut mittels Ammoniumchlorid lysiert, die andere Methode bediente sich der Isolierung reiner Granulocyten mittels eines Percoll-Gradienten. Die letztere Methode erwies sich als zuverlässig, einfach und hinreichend schnell für eine Anwendung in der Routine.

\section{Introduction}

Polymorphonuclear leukocytes' are the organism's first line of defense against many microorganisms. The ability of neutrophilic granulocytes to adhere to the surface of blood vessels, their diapedesis from the blood stream into regions of inflammation, and their properties of phagocytosis and killing of microorganisms are based upon a variety of highly complex cellular reactions. Various functional disorders of the granulocyte, both genetically determined and acquired, have been described in the literature $(1-5)$.
The present study examines in detail the measurment of chemiluminescence as an analytical tool for assessing oxidative reactions during phagocytosis under a variety of experimental conditions.

In 1972, Allen observed that neutrophilic granulocytes emit photons during phagocytosis (6). The interaction of granulocytes and other phagocytosing cells with phagocytosable particles results in an activation of oxygen-dependent metabolic pathways (respiratory burst, (7)); glucose turnover, in particular, is markedly increased via the hexose monophosphate shunt. As a result of the activation of a 
NADPH-oxidase, which is a membrane bound enzyme, superoxide anion radicals are produced, which, in turn, form highly reactive intermediates of oxygen such as hydrogen peroxide, hypochloric acid, hydroxyl radicals, and singlet oxygen $(6,8-12)$. These reactive oxygen species can occur in an electronically excited state (e.g., singlet oxygen) or generate excited intermediates by reaction with phagocytosable components. The intermediates relax and, in the process, emit photons. These photons can be used for quantitative determination. Since the application of 'native' chemiluminescence however, is hampered by several technical problems (e.g., extremely low photon yield), high cell densities are necessary. One additional problem is that the emitted light stems from different reactions and therefore has a broad energy spectrum $(14,15)$.

These analytical problems can be overcome by using chemilumigenic substrate probes $(16,17)$. One of the most common chemilumigenic substrate probes used to measure phagocytic activity is luminol (5amino-2,3-dihydrophthalazine-1,4-dione), which is oxidized by reactive oxygen species via excited intermediates to 3-aminophthalate. The transition of the intermediates to the ground state is accompanied by emission of light in a narrow frequency range $(425 \mathrm{~nm})$ (18). The reactive oxygen compounds formed during phagocytosis serve as the oxidizing agent. The emitted photon yield can be increased by a factor of approximately 1000 by the addition of luminol. Therefore, only a small number of granulocytes (approx. 104) are needed for the test system. The small samples of blood necessary for measurement are advantageous, for example in newborns, or patients with neutropenia where only a limited number of granulocytes are available. In recent years, various groups of researchers have used luminol-enhanced chemiluminescence to measure the functional activity of granulocytes (e.g., 19-22) or, with constant granulocyte concentration and variable amounts of serum, the opsonic capacity of the serum $(19,20,23,24)$. In such techniques, the granulocytes are isolated from the blood by different standard procedures (e.g., dextran sedimentation, Ficoll-Hypaque). Since many of these techniques are time consuming, some researchers have attempted to measure luminol-dependent chemiluminescence directly in whole blood samples, utilizing the ultrasensitivity of this method. Some groups measured only slightly"diluted blood samples (end dilution, approx. $1: 5)$; the results obtained with low dilutions, however, are influenced by various cellular and molecular components of whole blood (25-29). Other teams used highly diluted blood samples (end dilution, $1: 20-1: 5000)(30-32)$.
Experimental data on the measurement of phagocytosis-dependent chemiluminescence in whole samples under a variety of conditions are presented. Although the advantages of this technique are clear (i.e., no sample preparation, possibility of automatization of test system), the results, particularly in slightly diluted blood samples, are far from exact. Procedures therefore were sought which would eliminate these disadvantages, but which would not require an overly time-consuming cell preparation. In the first system, the quench effect was avoided by erythrocyte lysis, a method which also ensures rapid isolation of the total leucocyte fraction. Finally pure granulocytes were isolated with a modified Percoll method.

\section{Materials and Methods}

Chemicals and media:

Zymosan A: Sigma Munich/FRG; Luminol (5-amino-2,3-dihydro-1,4-phthalazinedione), $1 \mathrm{mmol} /$ : Lumac, Basel/Switzerland; PMA (4- $\beta$-phorbol-12-myristate-13-acetate), Sigma, Munich/ FRG; PBS (phosphate-buffered saline $+\mathrm{Ca}^{++}+\mathrm{Mg}^{++}$): $\mathrm{Se}-$ romed, Munich/FRG; Dulbecco's modified Eagle's medium + HEPES: Boehringer, Mannheim/FRG.

\section{Preparation of opsonized zymosan}

$600 \mathrm{mg}$ of zymosan were suspended in $60 \mathrm{ml}$ of $9 \mathrm{~g} / \mathrm{NaCl}$, stirred overnight, and homogenized with a Potter-Elvehjem apparatus. After centrifugation (10 $\mathrm{min}, 2000 \mathrm{~g}$ ), the zymosan was incubated with freshly drawn serum $\left(30 \mathrm{~min}, 37^{\circ} \mathrm{C}\right)$. After a second centrifugation, the opsonized zymosan pellet was washed and resuspended in $12 \mathrm{ml}$ of $9 \mathrm{~g} / \mathrm{l} \mathrm{NaCl}$. The resulting suspension wàs divided into several $150 \mu \mathrm{l}$ samples and stored at $-20^{\circ} \mathrm{C}$.

\section{Chemiluminescence assay}

\section{Whole blood methods}

I. The test system according to Kato (26) was performed as follows:

$100 \mu \mathrm{l}$ blood (10 IU/ml heparin) $+400 \mu \mathrm{l}$ buffer (Dulbecco's modified Eagle's medium + HEPES, pH 7.4; or PBS, pH 7.2) + $10 \mu \mathrm{l}$ luminol $(0.2 \mathrm{mmol} / \mathrm{h})$ were incubated for 10 minutes at $37^{\circ} \mathrm{C}$. Thereafter, $10 \mu \mathrm{l}$ zymosan $(1 \mathrm{mg})$ were added to the test system.

II. The test systems according to Allen $(31,32)$ were performed as follows:

a) $100 \mu \mathrm{l}$ EDTA blood were diluted with $900 \mu \mathrm{l}$ PBS $+1 \mathrm{~g} / \mathrm{glu}-$ cose $+1 \mathrm{~g} / \mathrm{l}$ albumin. $100 \mu \mathrm{l}$ of this dilution were incubated with $1.7 \mathrm{ml}$ PBS in the presence of $20 \mu \mathrm{l}$ luminol $(0.2 \mathrm{mmol} / \mathrm{l}) 10 \mathrm{~min}$, $37^{\circ} \mathrm{C}$ ). Phagocytosis was started by adding $20 \mu$ l opsonized zymo$\operatorname{san}(50 \mathrm{~g} / \mathrm{l})$.

b) In a second system, EDTA blood was diluted 1:100.50 $\mu$ l of this dilution were incubated using the system described above.

\section{Methods using granulocyte preparations}

III. Lysis of erythrocytes for the isolation of leukocytes

$250 \mu$ l of EDTA blood were incubated with $5 \mathrm{ml}$ of ice-cold $\mathrm{NH}_{4} \mathrm{Cl}$ solution $\left(8.3 \mathrm{~g} / \mathrm{NH} \mathrm{NH}_{4} \mathrm{Cl}, 37 \mathrm{mg} / \mathrm{Na}\right.$ EDTA, $1 \mathrm{~g} / \mathrm{h}$ $\mathrm{KHCO}_{3}$ ) for 5 minutes. After centrifugation ( $5 \mathrm{~min}, 200 \mathrm{~g}$ ), the cells were washed once, resuspended in phosphate-buffered saline (PBS, $+1 \mathrm{~g} / 1$ albumin $+1 \mathrm{~g} / 1$ glucose), and adjusted to $3 \times 10^{8}$ granulocytes per liter. 


\section{Chemiluminescence test conditions}

$100 \mu l$ of cell suspension ( $3 \times 10^{8}$ granulocytes per liter) plus $1700 \mu \mathrm{l}$ phosphate buffered saline (PBS $+1 \mathrm{~g} / \mathrm{l}$ albumin $+1 \mathrm{~g} / \mathrm{l}$ glucose) plus $20 \mu$ l of luminol $(0.2 \mathrm{mmol} / \mathrm{l})$ were preincubated for 10 minutes at $37^{\circ} \mathrm{C}$. The reaction was initiated by adding $20 \mu \mathrm{l}$ of opsonized zymosan $(50 \mathrm{~g} / \mathrm{l})$.

\section{Preparation of purified granulocytes}

The granulocytes were isolated with a modified procedure according to Hjorth (33).

\section{Preparation of step gradients}

12 polystyrene tubes (capacity, $4 \mathrm{ml}$ ) were filled with $1 \mathrm{ml}$ of approximatcly $70 \%$ Percoll- $\mathrm{NaCl}$ solution $\left(\mathrm{n}_{\mathrm{D}} 2 \mathrm{O}=1.3477\right.$; refractometer, Zeiss, Oberkochen/FRG). $1 \mathrm{ml}$ of an approximately $55 \%$ Percoll- $\mathrm{NaCl}$ solution $\left(\mathrm{n}_{\mathrm{D}} 2 \mathrm{O}=1.3450\right)$ was layered over this with a $1 \mathrm{ml}$ syringe. The hydrostatic pressure of the Pcrcoll solution ensured automatic preparation of the gradients. Parallel preparation of 12 gradients therefore was possible within approximatcly 15 minutes. The gradients can be stored for 1 to 2 days in the cold-storage room.

\section{Isolation of granulocytes}

$500 \mu \mathrm{l}$ of EDTA blood were applied to the gradients and centrifuged at $20^{\circ} \mathrm{C}$ for 10 minutes $(350 \mathrm{~g})$. During this time, the erythrocytes settled to the bottom and the granulocytes collected on the boundary layer between the two density steps, which were well separated from the mononuclear fraction and the platelet-rich plasma. After withdrawal of the supernatant layer, the granulocyte zone was removed, suspended in $9 \mathrm{~g} / \mathrm{NaCl}$, and washed once $(5 \mathrm{~min}, 350 \mathrm{~g})$. The cells were resuspended in phosphate buffered saline (PBS, $+1 \mathrm{~g} / \mathrm{l}$ albumin $+1 \mathrm{~g} / \mathrm{glucose}$ ) and adjusted to $3 \times 10^{8}$ granulocytes per liter (cell viability, $99 \%$ on trypan blue test; leukocyte contamination, $1 \%-2 \%$ ). The erythrocyte: granulocyte ratio was $0.2-0.5: 1$.

Under selected conditions, erythrocytes do not always settle to the bottom, i.e., in approximately $15 \%$ to $20 \%$ of all investigated patients and $5 \%$ to $7 \%$ of all "healthy" individuals. In such cases, there are two possible methods of correction: $\mathrm{NH}_{4} \mathrm{Cl}$ lysis of the erythrocyte-contaminated granulocyte suspension (no effect on chemiluminescence measurements) and separation of EDTA blood in a parallel run via a second Percoll gradient of lower density (step $1: n_{D} 20=1.3468 ;$ step $\left.2: n_{D} 20=1.3450\right)$. This second method was finally used, providing additional information about the sedimentation pattern of the blood cells.

\section{Chemiluminescence test conditions}

$100 \mu$ l of the granulocyte suspension plus $500 \mu \mathrm{l}$ of phosphate buffered saline (PBS $+1 \mathrm{~g} /$ glucose $+1 \mathrm{~g} / \mathrm{l}$ albumin) plus $50 \mu \mathrm{l}$ luminol $(0.2 \mathrm{mmol} / \mathrm{l})$ were preincubated for 10 minutes at $37^{\circ} \mathrm{C}$. The reaction was initiated by adding $20 \mu$ opsonized zymosan $(50 \mathrm{~g} / 1)$.

\section{Other methods}

Differential blood counting was carried out with Sangodiff (Merck, Darmstadt/FRG).

Leukocytes were counted in an ai 134 cell counter (dilab, Karlsruhe/FRG).

Chemiluminescence assay was performed on a Biolumat (LB 9505; Berthold, Wildbad/FRG). The results were evaluated with a model 43 teletype or an Apple II using the program "Bio".

Granulocytes, mononuclear fraction, and erythrocytes were isolated according to the Percoll method described by Hjorth (33).

Platelets were prepared by differential centrifugation as described in 1.c. (26).

\section{Results}

\section{Method I}

(Dilution of blood samples by approximately $1: 5$ according to Kato (26)).

\section{Course of chemiluminescence response}

The chemiluminescence curves of zymosan phagocytosis reported by Kato extended over roughly a 40minute period. When the reaction is followed for a longer period of time, a second peak appears after approximately 120 minutes which, in the selected test system, is somewhat higher than the first peak (fig. 1). Figure 1 shows the course of the chemiluminescence response during zymosan phagocytosis; the response was measured immediately after blood collection and again after storage of the blood sample at room temperature for 150 minutes. The results showed a sharp increase of the first peak and a decrease in the second. The height of the first peak can be taken as an indicator of phagocytic activity in response to zymosan. The second peak is probably caused by erythrophagocytosis (47).

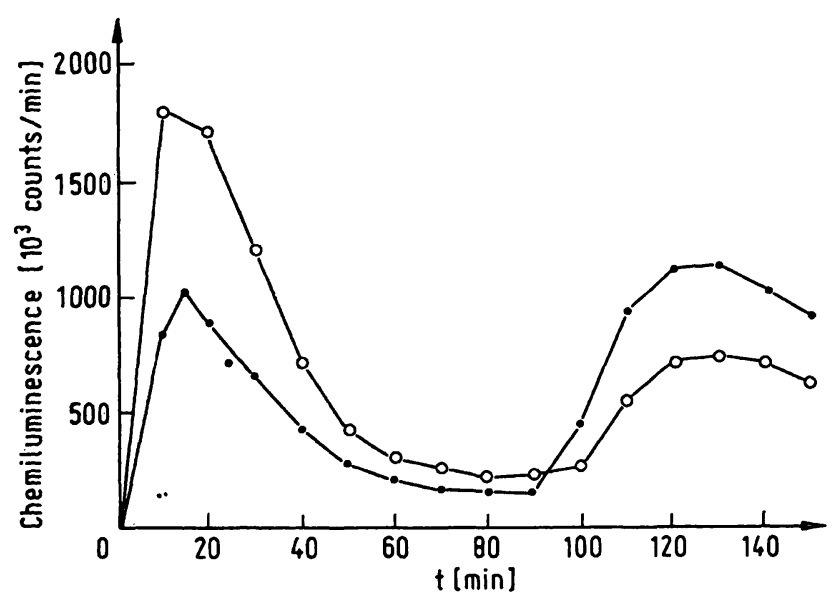

Fig. 1. Chemiluminescence response of whole blood samples (1:5 dilution) in the phagocytosis of zymosan. Points: Immediately after collection of blood. Empty circles: After storage of blood for 150 minutes at room temperature.

\section{Quench effects caused by erythrocytes}

The high erythrocyte concentration in the test system led to marked quench effects. Since the available measurement instruments are ultrasensitive, the problem is not the reduced photon yield per se, but rather the different haematocrit values and granulocyte-erythrocyte ratios of the blood samples. To study this situation (fig. 2), an experiment was car- 


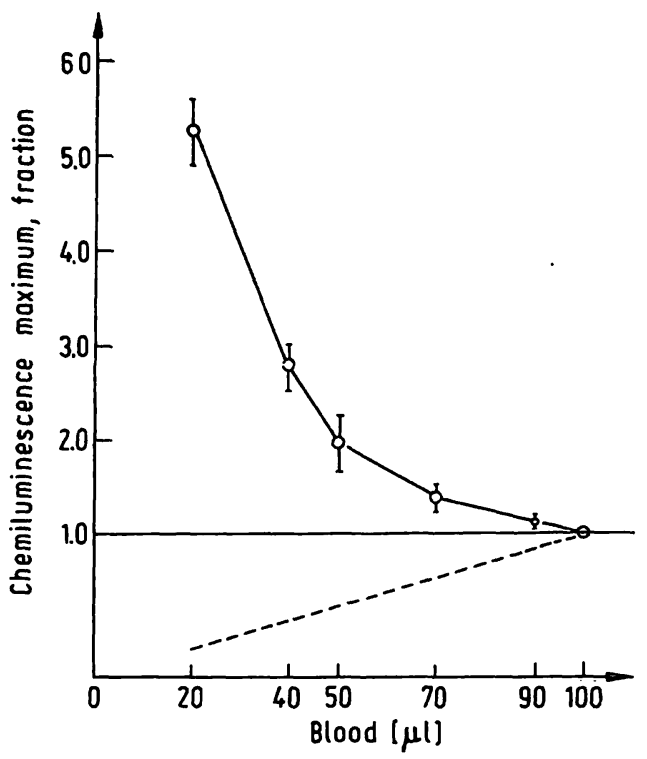

Fig. 2. Effect of different erythrocyte concentrations on photon yield fraction (compared to unquenched probes). Empty circles: Actual value (quenched probe).

Dashed line: Theoretical value (unquenched probe).

ried out based on the linear dependency between the height of the maximum and granulocyte density during phagocytosis (see fig. 7). Different quantities of whole blood $(20-100 \mu \mathrm{l})$ were adjusted to a constant test volume $(520 \mu \mathrm{l})$. To eliminate different opsonization effects, each test mixture contained the same serum fraction. Assuming the theoretical absence of a quench effect, the photon yield should be proportional to the quantity of added whole blood, e.g. the photon yields from mixtures containing $20 \mu \mathrm{l}, 40 \mu \mathrm{l}$ and $100 \mu \mathrm{l}$ whole blood should be in the ratio $2: 4: 10$. In reality, the smaller volumes of whole blood gave relatively higher yields of photons. The values obtained for the individual dilutions were expressed in percent and compared to the theoretical values. Blood from four different donors with approximately the same erythrocyte and granulocyte numbers and ratios were assayed. In another set up, EDTA blood was centrifuged, the plasma drawn off, and the cells pellet resuspended in buffer to yield the same volume. $20-100 \mu \mathrm{l}$ of the blood cell suspension was used, as described, for the test with opsonized zymosan as the phagocytosable particle. The results obtained in this test were practically the same (data not given).

\section{Effect of opsonization on chemiluminescence signal}

The contact between the phagocytosable zymosan and the serum leads to opsonization of the zymosan and therefore facilitates the uptake of zymosan by the granulocytes. This fact is related to enhancement of the chemiluminescence signal. When all other parameters in the test system are held constant and only the serum is varied, the opsonic capacity should be determinable with chemiluminescence. A more exact evaluation of the serum, however, indicates the presence of several other substances that have a strong modulating effect on the chemiluminescence response $(34,35)$. The following experiments were carried out to confirm this situation (fig. 3 ). The quantity of serum and the type of zymosan opsonization were varied in a standard: test system $(100 \mu \mathrm{l}$ granulocytes $\left(3 \times 10^{8}\right.$ cells per liter $)+50 \mu$ l luminol $(0.2 \mathrm{mmol} / \mathrm{l})$; total volume after addition of serum and PBS, $670 \mu \mathrm{l}, \mathrm{pH} 7.4)$. The maximum of the chemiluminescence signal (counts/min) was used as characteristic measurement parameter.

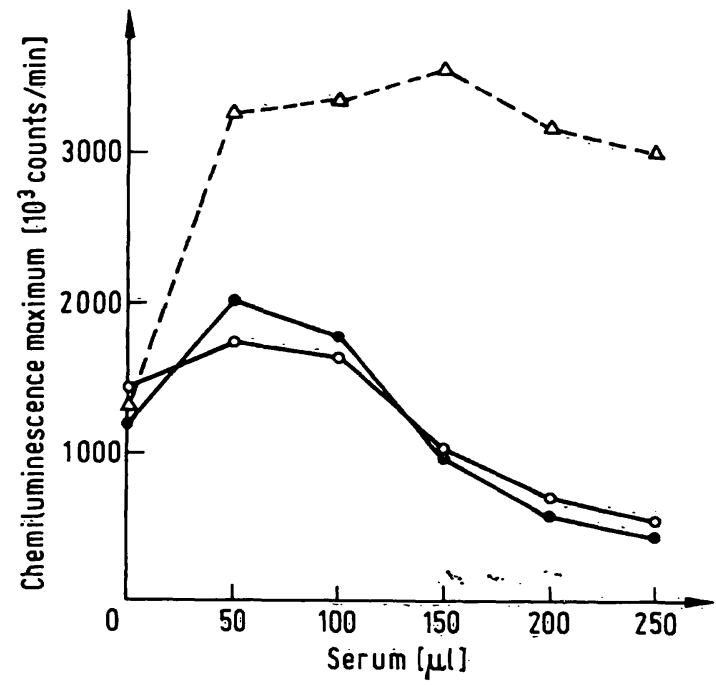

Fig. 3. Effect of serum on chemiluminescence response in phagocytosis of zymosan under different opsonization conditions.

Triangles: Test a, extẹnal opsoniżation, removal of serum.

Points: Test b, external opsonization without removal of serum.

Open circles: Test $c$, direct incubation.

Test $a$

$20 \mu \mathrm{l}$ zymosan $(50 \mathrm{~g} / \mathrm{l})$ were added to $0,50,100$, $150,200,$. or $250 \mu \mathrm{l}$ of fresh serum; PBS was added to yield a volume of $500 \mu \mathrm{l}$, and the suspension was externally opsonized for 30 minutes at $37^{\circ} \mathrm{C}$. The suspension was then centrifuged, the excëss serum drawn off, and the opsonized zymosan resuspended in buffer to yield a total volume of $500 \mu$ l. This sample was mixed with the granulocytes and chemiluminescence measured. 


\section{Test $b$}

The preparation was carried out in the same way as described above, except that the entire suspension was used in the test system instead of centrifuging off the serum after 30 minutes of opsonization.

\section{Test $c$}

In this test system, various amounts of serum (0$250 \mu \mathrm{l})$ were directly incubated with the granulocytes and the zymosan.

As figure 3 shows, concurrent effects are apparently responsible for the formation of the chemiluminescence signal. Due to the opsonization of zymosan, the chemiluminescence signal is increased by the presence of serum in the test mixture. On the other hand, serum causes a reduction of the photon yield in the test system, as tests b and c clearly indicate. The slight reduction of measured maxima (counts/ min) with increasing serum fraction in test a can probably be attributed to residual "contamination" of the serum after centrifugation (opsonized zymosan was not washed to avoid substance loss during centrifugation).

\section{Method II}

(Dilution of blood by approximately $1: 200$ or $1: 4000$ according to Allen $(31,32)$ ).

Allen described two methods for measuring phagocytosis in whole blood using luminol as chemilumigenic substrate probe:

1. Test system with blood dilution of $1: 200$ (32);

2. Test system with blood dilution of 1:4000 (31).

These high dilutions supposedly eliminate quench effects. In contrast to the technique with $1: 5$ dilution (Kato (26)) both these methods use opsonized zymosan; therefore only the cellular aspect of phagocytosis is evaluated. Allen's studies were carried out with a test volume of $2000 \mu$ l (dilution of blood samples, 1:200) using a LSC. The results are not optimal when these conditions are transferred to the Biolumat; reduction of test volume with all other parameters held constant results in a significantly enhanced chemiluminescence signal and earlier appearance of the maxima (counts/min) (fig. 4).

\section{Quench effects}

To study whether quench effects also appear in this test system, blood samples were used from the assay with 1:4000 dilution according to Allen (test vo-

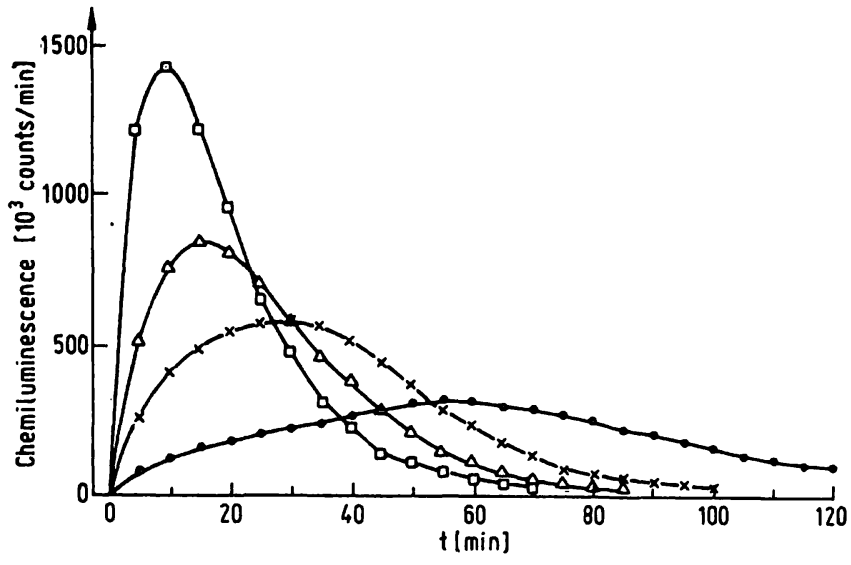

Fig. 4. Effect of test volume on chemiluminescence response of blood (predilution, 1:10) in phagocytosis of opsonized zymosan.

Test mixture: $100 \mu$ l EDTA blood (dilution, $1: 10$ )

$+50 \mu$ l luminol +

$20 \mu l$ opsonized zymosan;

buffer added to yield different total volumes:

- $1870 \mu \mathrm{l} ; \times \longrightarrow 1270 \mu \mathrm{l}$;

$\triangle \longrightarrow \triangle 970 \mu \mathrm{l} ; \square-\square 670 \mu \mathrm{l}$

lume, $2000 \mu \mathrm{l})$. The test was carried out according to the same principle already described for the Kato method (The actual photon yield was compared with the theoretical values that would have been obtained in the absence of quench effects). Table 1 shows the results obtained using blood from four subjects without consideration of the differing haematocrit, erythrocyte, and granulocyte counts. As the table shows, quench effects are also present; it should be noted that the granulocyte-erythrocyte ratio in the test system is approximately $1: 1000$. The supposition that the quench effect could possibly be eliminated by the attachement of the granulocytes to the vessel wall of the incubation vial (31) was not confirmed. Granulocytes $\left(3 \times 10^{4}\right.$ cells) were incubated in an incubation vial for 10 minutes at $37^{\circ} \mathrm{C}$. This sample was then carefully transferred to a second vial. The empty vial with granulocytes, which may possibly attach to the surface, was filled with fresh incubation buffer to yield the original volume. Subsequent incubation of

Tab. 1. Studies of quench effect in highly diluted blood samples

\begin{tabular}{llllll}
\hline $\begin{array}{l}\text { Test } \\
\text { volume } \\
(\mu l)\end{array}$ & $\begin{array}{l}\text { Theo- } \\
\text { retical } \\
(\%)\end{array}$ & $\begin{array}{l}\text { Sample } \\
(\%)\end{array}$ & $\begin{array}{l}\text { Sample } \\
(\%)\end{array}$ & $\begin{array}{l}\text { Sample } \\
(\%) \\
(\%)\end{array}$ & $\begin{array}{l}\text { Sample } \\
(\%) \\
(\%)\end{array}$ \\
\hline 100 & 100 & 100 & 100 & 100 & 100 \\
90 & 90 & 101 & 100 & 106 & 102 \\
70 & 70 & 127 & 136 & 121 & 130 \\
50 & 50 & 134 & 127 & 131 & 142 \\
40 & 40 & 139 & 128 & 152 & 177 \\
20 & 20 & 160 & 153 & 192 & 196 \\
\hline
\end{tabular}


both samples with opsonized zymosan showed only approximately $15 \%$ of the chemiluminescence recorded for the first vial.

\section{Effect of different zymosan concentrations on chemi- luminescence signal}

Figure 5 shows the effect of different zymosan concentrations on the height of the measured maximum (counts/min). A good linear relationship was established with 5 to $30 \mu \mathrm{l}$ opsonized zymosan per test system $(50 \mu$ l blood (prediluted $1: 1000)+50 \mu l$ luminol $(0.2 \mathrm{mmol} / \mathrm{l})+500 \mu \mathrm{l}$ phosphate buffered saline).

In contrast to the quench effects where an exact correction is very difficult, correction of the signal does appear to be possible in this case, even in probes with widely varied granulocyte-zymosan ratios. The appearance of the maximum, however, depends to great extent on this ratio and therefore is not well suited for use as a characteristic parameter.

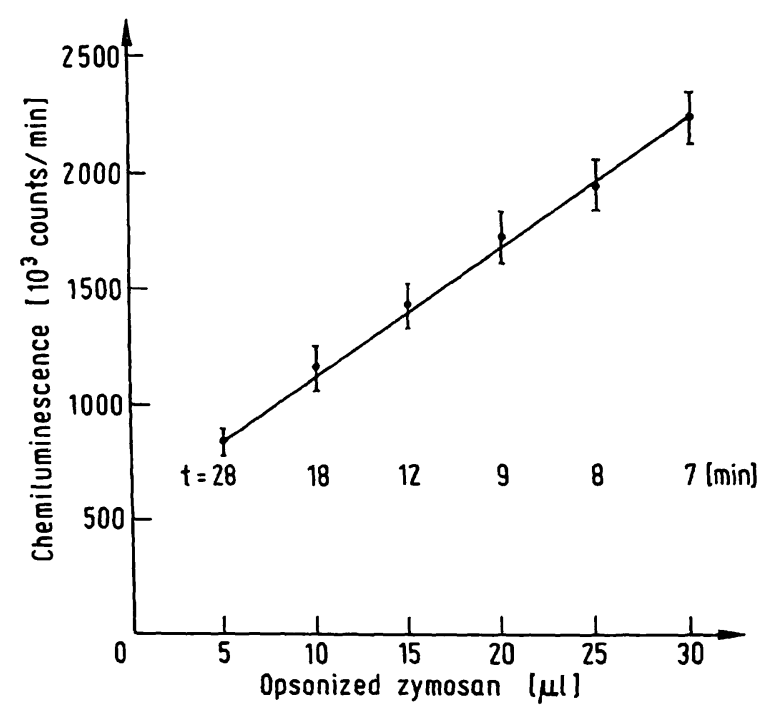

Fig. 5. Dependence of measured maxima (counts/min) on quantity of opsonized zymosan in temporal association with appearence of maximum $(n=3)$.

\section{Method III}

(Preparation of leukocytes after erythrocytes lysis with $\mathrm{NH}_{4} \mathrm{Cl}$ ).

\section{Course of chemiluminescence response}

The course of chemiluminescence in the described test system is shown in figure 6 . The figure shows the course of the chemiluminescence signal during phagocytosis of opsonized zymosan in healthy persons;

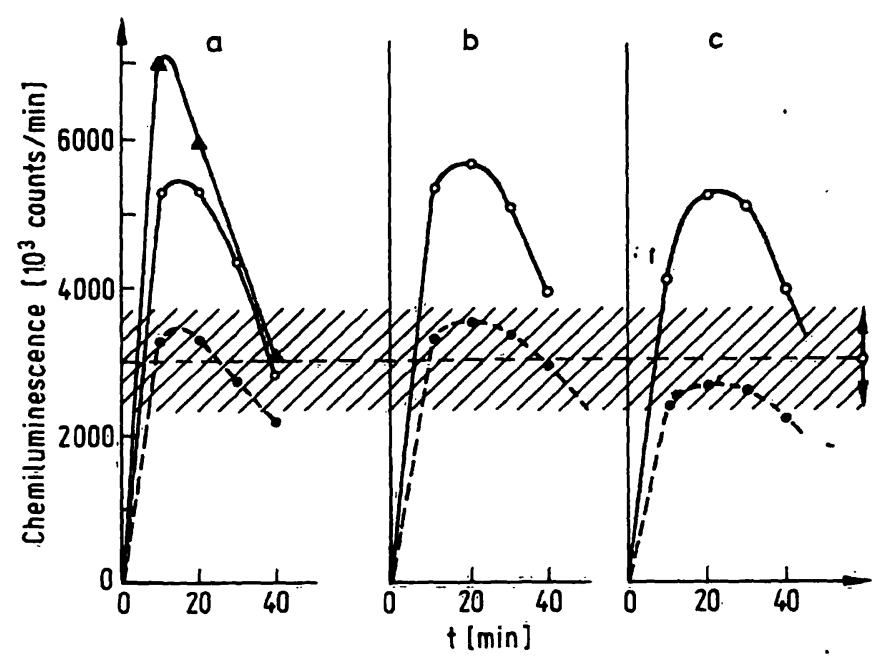

Fig. 6. Course of chemiluminescence response in phagocytosis of zymosan (leukocyte preparation).

Hatching: Normal values $(n=14)$.

Points: Daily controls.

Triangles: Man with subcorneal pustulosis.

Open circles: Male psoriatic investigated on 3 consecutive days $(a, b, c)$.

as an example of clinical application, the course of the chemiluminescence signal is also shown in patients with common dermatological diseases (a man with subcorneal pustulosis, Sneddon-Wilkinson, and a male psoriatic). Leukocytes from healthy subjects served as controls on each day of the experiment. The control values were in the range determined for the normal group using the same opsonized zymosan charge; using the same ratio of cell density to opsonized zymosan, the values of the patients were markedly higher than those of the controls. The different blood pictures were investigated prior to the measurement of chemiluminescence so that the gra-

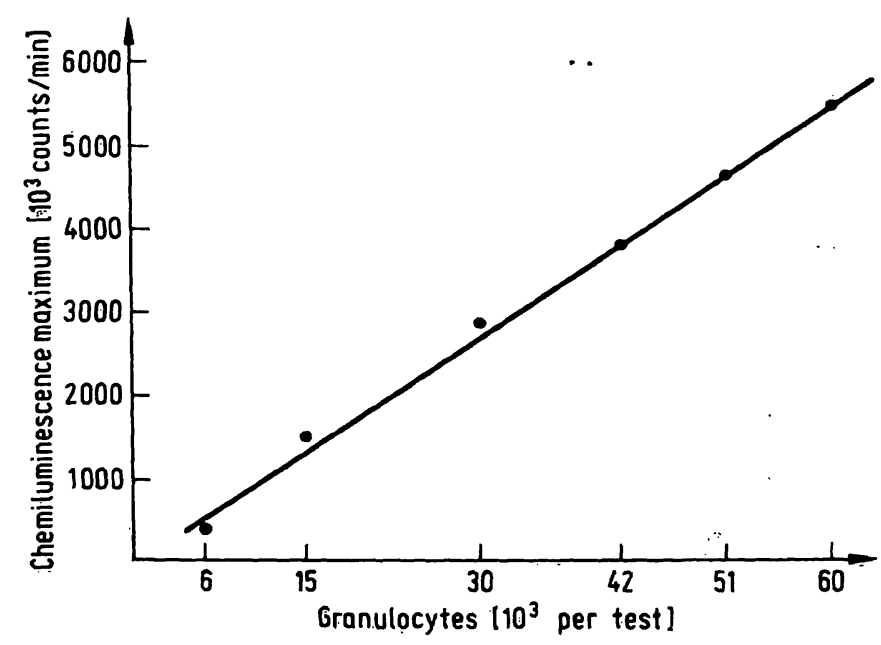

Fig. 7. D́ependent relationship between measured maxima (counts/min) and number of granulocytes $(0.6-6.0 \times$ $\left.10^{4}\right)$ in incubation with opsonized zymosan $(20 \mu \mathrm{l})$. 
nulocyte number could be held constant in all test assays and the time of the measured maximum (counts/min) used as a characteristic reaction parameter.

Linear dependencies exist between chemiluminescence maxima ( $20 \mu$ l opsonized zymosan; range, 0.6 $-6.0 \times 10^{4}$ cells/test) and cell density (fig. 7), as well as between integrated counts and cell density. Thus, variations in the granulocyte-opsonized zymosan ratio apparently do not affect the height of the maximum, which remains linearly proportional to cell density. The time at which the maximum appears, however, is influenced by alterations in granulocyte function.

Establishment of normal values and a few characteristic data

14 healthy male and female subjects (age range, 20-40 years) were examined over a 3-week period. The following values for the characteristic chemiluminescence phagocytosis parameter were established with the opsonized zymosan charge "1/82":
Measured maximum (counts/min):

Time of measured maximum:

Integrated counts after 60 minutes:
$3031 \pm 657 \times 10^{3}$

20-26 minutes

$13.8 \pm 2.04 \times 10^{7}$

\section{Precision}

Measurement-to-measurement variations were examined in 6 identical tests run parallel in the 6 channels of the Biolumat $( \pm 4 \%)$.

\section{Effect of storage of EDTA blood at room tempera- ture}

Compared to measurements made directly after collection of blood samples ( $100 \%$ value), values after 2-hour storage at room temperature were $112 \pm$ $13 \%(n=10)$. A $75 \%$ to $80 \%$ reduction in measured maxima was recorded in isolated cells that were allowed to stand for 1 hour at 0 to $4^{\circ} \mathrm{C}$ prior to chemiluminescence measurements.

\section{Effect of $\mathrm{NH}_{4} \mathrm{Cl}$ on chemiluminescence signal}

The following experiment was carried out to clarify the effect of the lysis medium on the granulocytes. The granulocytes were isolated with the Percoll method, washed, and resuspended in physiologic solution. $250 \mu \mathrm{l}$ samples of the granulocyte suspension $\left(3 \times 10^{8}\right.$ cells per liter) were mixed with either $5 \mathrm{ml}$ lysis medium or $5 \mathrm{ml}$ saline solution (control). After incubation for 5 minutes, the cells were centrifuged, washed, and adjusted to $3 \times 10^{8}$ cells per liter. The following values were obtained $(n=5$; the $\mathrm{NaCl}$ value was arbitrarily set at $100 \%$ in each pair of values):

\begin{tabular}{llc}
\hline & $\mathrm{NaCl}$ group & $\mathrm{NH}_{4} \mathrm{Cl}$ group \\
\hline Measured maximum & $100 \%$ & $102 \pm 13 \%$ \\
Time of maximum & $10-12 \mathrm{~min}$ & $10-12 \mathrm{~min}$ \\
Integrated counts $(60 \mathrm{~min})$ & $100 \%$ & $98 \pm 10 \%$ \\
\hline
\end{tabular}

\section{Evaluation}

The quench effect, one of the primary problems associated with whole blood methods, was successfuly eliminated with this method. In addition, the differential blood picture was prepared prior to chemiluminescence measurement to ensure a constant granulocyte concentration in the test system. Advance preparation of the differential blood picture, however, presents technical problems when large numbers of samples are to be evaluated. The Percoll method according to Hjorth (33) for the isolation of pure granulocytes therefore was subsequently used and modified so that suitable cells could be isolated for chemiluminescence measurement of phagocytosis within a short period of time.

\section{Method IV}

(Preparation of isolated granulocytes by the Percoll method)

\section{Course of chemiluminescence response}

Characteristic curves and the method of documentation, using the "BIO" program, are presented in figure 8: Duplicate assays are shown for 2 subjects using luminol as chemilumigenic substrate probe in channels 1 and 2 as well as 4 and 5; lucigenin (same concentration as luminol) was used as chemilumigenic substrate probe for the probes in channels 3 and 6 (subject 1 , patient with burns over $20 \%$ surface: subject 2, control).

In order to establish a test system with good photon yield, the following parameters were varied:

\section{a) Determination of a favourable granulocyte-zymo- san ratio}

The course of the measured maximum with different granulocyte densities dependent on the amount of 

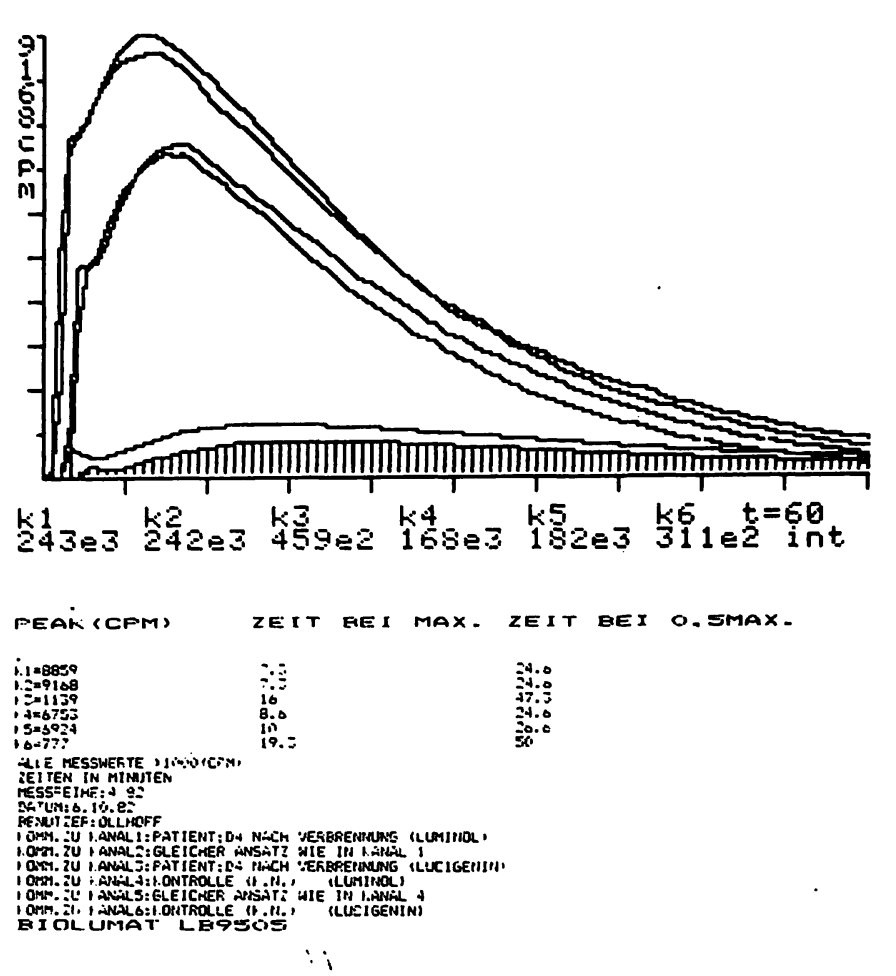

Fig. 8. Documentation of chemiluminescence measurement using "BIO" program with automatic scaling.

opsonized zymosan is shown in figure $9 \mathrm{a}$. Based on these data, an assay consisting of $20 \mu \mathrm{l}$ of opsonized zymosan $(50 \mathrm{~g} / 1)$ and $3 \times 10^{4}$ granulocytes was selected for the standard test system. The course of the integration curves for different granulocyte concentrations with $20 \mu \mathrm{l}$ opsonized zymosan is presented in figure $9 \mathrm{~b}$. In both cases, a linear relationship exists between the number of granulocytes and the photon yield. Since, in all our experiments, the chemiluminescence-detected reaction was terminated after 60 minutes, the integration of the counts in this interval was used as the characteristic measurement parameter in all subsequent experiments.

\section{b) Determination of suitable test volume}

Holding the other parameters $\left(4 \times 10^{4}\right.$ granulocytes, $50 \mu$ l luminol, $20 \mu l$ opsonized zymosan) constant, the total test volume was varied by adding increasing amounts of buffer:

\begin{tabular}{lll}
\hline $\begin{array}{l}\text { Total test } \\
\text { volume } \\
(\mu \mathrm{l})\end{array}$ & $\begin{array}{l}\text { Chemiluminescence } \\
\text { maximum } \\
\text { (counts/min) }\end{array}$ & $\begin{array}{l}\text { Time of chemiluminescence } \\
\text { maximum } \\
(\mathrm{min})\end{array}$ \\
\hline 670 & 5211 & 12 \\
1170 & 1901 & 24 \\
1670 & 1056 & 31 \\
\hline
\end{tabular}

Due to the measurement geometry of the instrument and the dilution of the reaction partners, the photon yield declines sharply as the test volume increases. A total test volume of $670 \mu \mathrm{l}$ was used in all subsequent experiments.

\section{c) Determination of a favourable luminol concentra- tion}

The test system consisted of $100 \mu l$ of granulocytes $\left(3 \times 10^{4}\right), 20 \mu$ l of opsonized zymosan, and varying amounts of $0.2 \mathrm{mmol} / \mathrm{l}$ luminol solution $(20,40,60$, $80,100 \mu \mathrm{l})$, and buffer ad $670 \mu \mathrm{l}$. A linear dependency exists between the luminol concentration and the photon yield in the investigated range (measured maximum, 1920 counts/min ( $20 \mu \mathrm{ll})$ to 7860 counts/ $\min (100 \mu \mathrm{l})) .50 \mu \mathrm{l}$ of luminol were used in the standard test system.

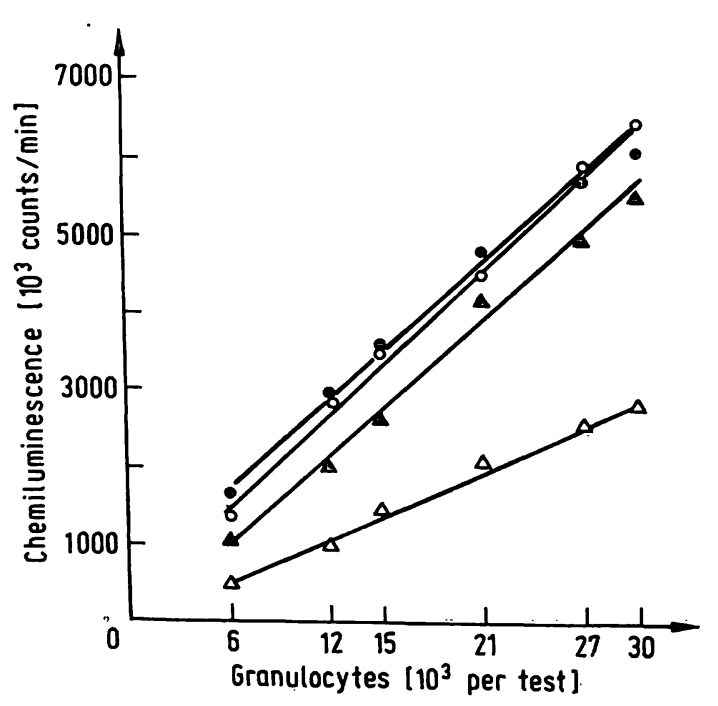

Fig. 9 a. Relationship between measured maxima (counts $/ \mathrm{min}$ ) of different granulocyte concentrations incubated with different amounts of opsonized zymosan.

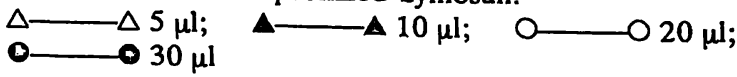

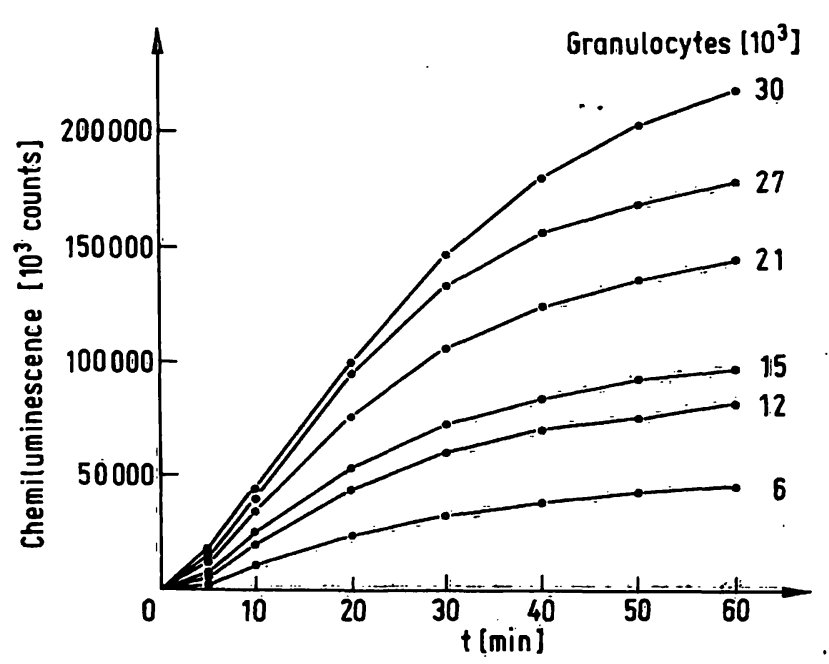

Fig. 9 b. Course of chemiluminescence integration curves of different granulocyte concentrations incubated with $20 \mu \mathrm{l}$ opsonized zymosan $(50 \mathrm{~g} /)$. -i 


\section{Determination of reference values}

Granulocytes from 18 healthy men and women collected over a period of 2 weeks were used for chemiluminescence measurement to determine the normal values for the selected test conditions and for a defined charge of opsonized zymosan (in described case, " $2 / 82 ")$. The blood specimens were collected in the morning and in the afternoon. Evaluation of blood specimens collected twice a day from 3 individuals indicated that the time of the blood collection had no effect on the chemiluminescence signal.

The following characteristic chemiluminescence parameters were established:
Mcasured maxima (counts/min):

Timc of maximum ( $\mathrm{min})$ :

Integration after $60 \mathrm{~min}$ :

Standard deviation of single measurement: $\pm 3.5 \%$
$5085 \pm 634 \times 10^{3}$

$8-1$

$15.1 \pm 2.1 \times 10^{8}$
EDTA blood can be stored for a few hours at room temperature without any perceivable change in the chemiluminescence signal of the granulocytes: Related to the starting value for immediately processed blood, the measured maxima (counts/min) after storage of the blood for 150 minutes at room temperature were $101+5 \%(n=6)$. A slight loss of activity was noted in isolated cells after $30 \mathrm{~min}$ storage on ice $(97+7 \%)$.

\section{Effect of Percoll on chemiluminescence signal}

The effect of Percoll in the test system was studied in the following experiments:

a) The granulocytes were isolated according to the Percoll method to determine the direct effect of Percoll. Aliquots were applied directly in the standard test system: In one case, the Percoll solution was centrifuged and the washing step (removal of Percoll from the cells) was omitted; in another case, the cells were washed as usual: The chemiluminescence response in the phagocytosis of opsonized zymosan (measured maxima, $113 \pm 10 \%$ compared to standard system, $n=3$ ) is slightly higher with Percoll in the test system than in a Percoll-free granulocyte preparation.

b) The leukocytes $\left(3 \times 10^{4}\right.$ granulocytes/test) were isolated with method III ( $\mathrm{NH}_{4} \mathrm{Cl}$ lysis) and incubated with $20 \mu \mathrm{l}$ of pure Percoll instead of opsonized zymosan. The photon yield obtained with the direct incubation of Percoll under the selected conditions was negligibly low.

c) The effect of Percoll was tested in another assay as follows: Leukocytes (isolated by method III) were divided into two samples. $0.5 \mathrm{ml}$ of one fraction (approx. $3 \times 10^{6}$ granulocytes corresponding approximately to the amount coming in contact with $1 \mathrm{ml}$ of $55 \%$ Percoll solution during Percoll centrifugation) was mixed with $1 \mathrm{ml} 9 \mathrm{~g} / \mathrm{l} \mathrm{NaCl}$ solution; $0.5 \mathrm{ml}$ of the other fraction was mixed with $1 \mathrm{ml}$ of a $55 \%$ Percoll solution, allowed to stand for 10 minutes at room temperature, and then centrifuged. The cells were washed and examined in the standard test system. The chemiluminescence response of cells incubated with Percoll was higher than of cells incubated without Percoll: the measured maximum was $121 \pm$ $8 \%(n=3)$ compared to the control which was arbitrarily set at $100 \%$.

\section{Relationship between chemiluminescence signal and opsonized zymosan}

Zymosan was opsonized with the serum of healthy individuals, as described in the section "Material and Methods". The preparation was sufficient for approximately 500 determinations. Since the opsonization capacity of each individual donor serum is different, a new normal control $(n=6-10)$ was always prepared when opsonized zymosan charges were changed. In the context of a test series, the obtained chemiluminescence values of the investigated patients were compared with those of each normal control group. In addition, granulocytes from a healthy subject, the values of which agreed with those of the normal group, served as control on each test day.

The following experiments were carried out with opsonized zymosan:

a) Some fresh zymosan samples were frozen and then thawed; some were immediately used without freezing for the chemiluminescence test. No differences in the photon yield could be established between frozen und fresh zymosan samples.

b) For theoretical reasons, the effect of the storage period on the quality of the zymosan cannot be precisely determined: no standardized granulocytes are available. However, since chemiluminescence responses for the same subject were very similar (maxima, $3476 \pm 298 \times 10^{3}$ counts $/ \mathrm{min}$ ) in 5 assays carried out at one-week storage intervals over a period of 5 weeks it is reasonable to assume that this storage period does not negatively effect the quality of opsonized zymosan.

\section{Example of a clinical application}

Various granulocyte dysfunctions developing after severe burn injuries have been detected with chemi- 
luminescence methods $(32,43,44)$. Our studies also confirmed the observation that granulocyte dysfunctions can be detected with chemiluminescence methods: As an example, the courses of the measured maxima (counts/min) for two patients who were admitted to hospital at the same time were followed for several days (patient 1 , burns over $20 \%$ of total body surface; patient 2 , third degree burns over $50 \%$ of total body surface) are shown in figure 10 . Granulocyte activity declined sharply within a few days in the severely burned patient, who died on the sixth postburn day, but increased slightly within a few days in the patient with burns over only $20 \%$ of the total body surface.

One interesting finding was observed in the patient with burns over $50 \%$ of the total body surface, after he was given fresh frozen plasma $(750 \mathrm{ml})$ on the third postburn day. While granulocyte activity on this day, prior to administration of fresh frozen plasma, was already sharply diminished, the activity of granulocytes isolated 5 hours after fresh frozen plasma administration was even higher than that of normal individuals. It therefore is entirely possible that the low granulocyte activity was conditioned by the qualitatively inferior serum of the burn patient (possibly due to the absence of certain components or the presence of toxic factors). This situation therefore

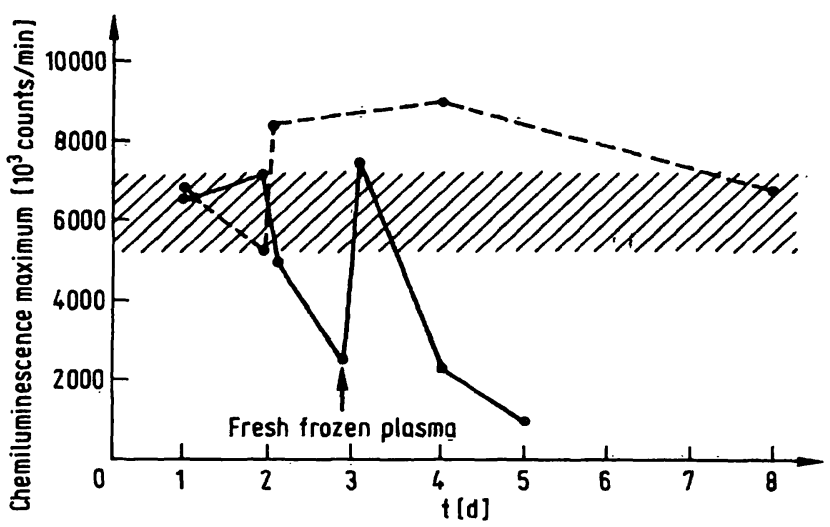

Fig. 10. Changes in measured maxima (counts/min) for two burn patients several days after the burn event.

Full line: Man with burns over $50 \%$ of total body surface.

Broken line: Man with burns over $20 \%$ of total body surface.

Hatched: maxima (counts/min) of daily controls.

was compensated by adding high quality serum. Granulocyte activity approximately 20 hours later was again markedly diminished (half time of granulocytes in blood, 6-7 hours (5).

In conclusion table 2 summarizes the characterized feature of the four test systems investigated.

Tab. 2. Comparison of 4 investigated methods with chemiluminescence measurement during phagocytosis of zymosan.

\begin{tabular}{|c|c|c|c|c|}
\hline & $\begin{array}{l}\text { I } \\
\text { Whole blood method } \\
\text { (dilution approx. 1:5) }\end{array}$ & $\begin{array}{l}\text { II } \\
\text { Whole blood method } \\
\text { (dilution approx. 1:4000) }\end{array}$ & $\begin{array}{l}\text { III } \\
\text { Whole blood } \\
\text { lysed with } \mathrm{NH}_{4} \mathrm{Cl}\end{array}$ & $\begin{array}{l}\text { IV } \\
\text { Granulocytes } \\
\text { (Percoll-method) }\end{array}$ \\
\hline Anticoagulants & Heparin, no EDTA & EDTA etc. & EDTA etc. & EDTA etc. \\
\hline Preparation of probes & - & - & $\begin{array}{l}35 \min ^{*} \text { ) } \\
\text { (with diff. } \\
\text { blood picture) }\end{array}$ & $25 \min$ \\
\hline Test system & $\begin{array}{l}\text { all blood cells }+ \\
\text { plasma }+ \text { zymosan }\end{array}$ & $\begin{array}{l}\text { all blood cells }+ \\
\text { opsonized zymosan }\end{array}$ & $\begin{array}{l}\text { all leukocytes }+ \\
\text { opsonized zymosan }\end{array}$ & $\begin{array}{l}\text { granulocytes }+ \\
\text { opsonized zymosan }\end{array}$ \\
\hline $\begin{array}{l}\text { Possible disturbances due to } \\
\text { serum } \\
\text { cell-cell interaction } \\
\text { quench effects } \\
\text { storage of blood }\end{array}$ & $\begin{array}{l}+ \\
+ \\
+ \\
+\end{array}$ & $\begin{array}{l}- \\
+ \\
+ \\
-\end{array}$ & $\begin{array}{l}- \\
+ \\
\overline{(-)}\end{array}$ & $\begin{array}{l}- \\
- \\
-\end{array}$ \\
\hline Necessary procedures & $\begin{array}{l}\text { measurement } \\
\text { diff. blood picture } \\
\text { correction }\end{array}$ & $\begin{array}{l}\text { measurement } \\
\text { diff. blood picture } \\
\text { correction }\end{array}$ & $\begin{array}{l}\text { measurement } \\
\text { lysis } \\
\text { diff. blood picture }\end{array}$ & $\begin{array}{l}\text { measurement } \\
\text { cell isolation } \\
\text { counting }\end{array}$ \\
\hline Necessary amount of blood (approx) & $100 \mu \mathrm{l}$ & $1-5 \mu l$ & $200 \mu \mathrm{l}$ & $500 \mu \mathrm{l}$ \\
\hline Granulocyte concentration per test & variable & variable & $\left.3 \times 10^{4 *}\right)$ & $3 \times 10^{4}$ \\
\hline Zymosan-granulocyte ratio & variable & variable & constant*) & constant \\
\hline
\end{tabular}

*) when differential blood picture is prepared prior to chemiluminescence measurement. 


\section{Discussion}

In recent years, chemiluminescence measurements have become increasingly important as an analytical method. Possible uses of this ultrasensitive method include assessing many metabolites and enzymes, monitorung functional activity of neutrophilic granulocytes, or measuring opsonic capacity of serum (32). The introduction of chemilumigenic substrate probes made it possible to enhance the sensitivity of the test system to such an extent that chemiluminescence can be measured in whole blood. We also evaluated test systems with slightly diluted blood samples and systems with highly diluted samples. The problems discussed first are those arising in association with chemiluminescence measurement of slightly diluted whole blood samples. The tests reported in the present study are based primarily on the test system introduced by Kato and coworkers (26).

The chemiluminescence signal obtained with this test system is predominantly a function of granulocyte density and activity as well as of the concentration of serum components with opsonic capacity. Direct utilization of the obtained chemiluminescence signal for characterization, however, is not possible. Since granulocyte density can vary considerably from sample to sample, the measurement values must be related to a constant granulocyte count. Similary, the serum must be corrected (i.e., opsonic concentration), depending on the haematocrit of the blood sample. Even after these corrections have been made, the chemiluminescence signal is still difficult to interpret. An abnormal value provides no information about whether the abnormality is of a cellular or humoral nature. Additional tests are necessary to clarify this point. A value in the normal range also does not provide absolutely reliable information about the functional state of the granulocytes or the humoral systems: a deficiency of any one component can elicit a partial and temporary compensation on the part of the other component, thus simulating normal conditions. Steven and coworkers (20), for example, described a case of neutropenia with increased granulocyte activity and depressed opsonic capacity. The opsonization defect would probably have gone undetected with a whole blood assay.

Finally, there are several other interfering factors in this test system. The primary interference is the pronounced quench effect produced by the erythrocytes; exact corrections, however, pose a major problem. The erythrocyte quenching of the chemiluminescence in figure 2 is an idealistic situation, because the tests were carried out using blood samples with approximately the same erythrocyte-granulo- cyte ratio. In practice, however, there is usually considerable variation in the erythrocyte-granulocyte ratios of the blood samples, a factor which additionally complicates correction.

The situation is impossibly complicated when all possible factors that interfere with the chemiluminescence response are taken into consideration.

At the cellular level, mention should be made of the contributions of platelets (36) and monocytes, and the strong dependency between the chemiluminescence signal and the storage period of the blood (fig. 1), a dependency which should be attributed to a granulocyte-platelet interaction in resting blood (26). In addition to opsonization effects, humoral effects are also numerous and may be, in part, functionally related to the phagocytosis process (e.g., the effect of $\mathrm{Ca}^{++}$ions) or may nonspecifically influence the chemiluminescence signal in the test system. Examples of this are the effect of the protein concentration in the test system (34); ceruloplasmin (35); substancès such as superoxide dismutase and catalase, which are possibly released by erythrocytes during incubation (37); chemotactic factors (38); some amino acids (tryptophan, tyrosine, cysteine (34)); and drugs such as acetylosalicylic acid (3941). Even though many of these influences play an insignificant role from a quantitative point of view, the many possible interferences nevertheless impossibly complicate the situation. This test system therefore should only be used for questions in which clearcut answers are to be expected, e.g., as screening tests for severe genetically determined granulocyte dysfunctions such as occur in chronic granulomatous disease or for myeloperoxidase deficiency, which elicits virtually no response in the luminol-enhanced chemiluminescence test system.

Most of the problems mentioned here can be avoided by the use of methods with highly diluted whole blood: The experimental simplicity of the system is preserved, the interfering effects of the serum do not occur because of the high dilution, and the interpretation of the chemiluminescence signal is easier. A few problems, however, cannot be completely eliminated even in this system: Granulocyte counts must still be corrected and the granulocyteopsonized zymosan ratio varies. This variation in the ratio interferes with the chemiluminescence signal: Under the selected test conditions, this interference, however, does not effect the height of the measured maximum, but it does influence the time at which the maximum is reached (fig. 5). Finally, the quench effect by the erythrocytes cannot be entirely eliminated even in the highly diluted test systems (approx. 
1:4000) using the Biolumat. The supposition that most of the granulocytes attach to the vessel wall and therefore escape the quench effect was not confirmed in our investigations.

The quench effect could possibly be further depressed by a higher dilution of the test mixture (42). The low granulocyte count, however, becomes a limiting factor at dilutions exceeding 1:4000.

By way of summary, methods with highly diluted whole blood are always preferable to methods with lower dilutions, although these measurement methods are also problematic. We therefore attempted to find other systems which would eliminate these problems; the requirements of such systems are 1) avoidance of the problems associated with whole blood methods and 2) rapid isolation of leukocytes.

In the first assay, these requirements were met in whole blood samples by erythrocyte lysis. Under the selected conditions, this procedure had no influence on the quality of the granulocytes (see to the contrary, l.c. (46)). The quench effect was so effectively eliminated that cells were available for the test within approximately 15 minutes. For additional optimization, the differential blood picture was prepared prior to the chemiluminescence measurement so that the same granulocyte density, and therefore a constant granulocyte-zymosan ratio, were present in each test assay. While this system ensures reproducible results, interactions can also be detected. The slight rise in activity with EDTA blood stored at room temperature would tend to indicate that such interactions are actually present, even if only to a slight degree. We also observed that when granulocyte fractions isolated with the Percoll method and mononuclear cells containing platelets are incubated together, the chemiluminescence response is always $15 \%$ to $20 \%$ higher than when both fractions are incubated separately and their chemiluminescence signals added together. The same effects described in connection with the storage of whole blood may well be responsible for this higher value (fig. 1).

A pure granulocyte fraction, on the other hand, can be obtained by separation of the cells via a Percoll step gradient. Under these conditions, optimal standardization of the test system is possible: Only the granulocytes and the phagocytosable particle are present as reaction partners. The modulating effects of other substances on phagocytosis can be easily tested by adding these substances to the test assay. Contrary to Hjorth's original instructions, the isolation volume was reduced since only small amounts of granulocytes are required for the luminol-enhanced system and $\mathrm{NH}_{4} \mathrm{Cl}$ lysis is unnecessary. This then means that cells with a grade of purity sufficient for chemiluminescence measurement (contamination by only a few erythrocytes) are available for the test system within approximately 25 minutes. The preparation of the Percoll gradients is not time consuming; parallel gradients can be performed rapidly without technical problems and the samples can be kept for some time in the cold-storage room. The method is also well suited for documentation, because, in contrast to most other methods, the graphic registration of the chemiluminescence course does not require correction. Direct comparison of the samples therefore is possible. On the basis of the reasons cited in the present study and our experience with this and other methods, we consider this procedure to be particularly well suited for obtaining clear, sensitive and reproducible responses for oxidative processes occurring during phagocytosis.

The following two problems still need to be discussed:

1. The erythrocytes of some patients do not settle to the bottom under the selected conditions. To prevent this, a parallel run with a lower Percoll density was always carried out in patient asšäys: As a result, pure granulocyte preparations were obtained in all investigated cases.

2. According to Hjorth, the chemiluminescence response of granulocytes isolated with the Percoll method does not differ from that of granulocytes obtained with the dextran method (33). Our studies, however, indicated that Percoll is not entirely inert. On the other hand, this effect should equally influence controls and test specimens.

\section{Acknowledgement}

Authors wish to thank Mrs. Ganger for expert technical assistance. 


\section{References}

1. Root, R. K. \& Beeson, P. B. (1982) Klin. Wochenschr. 60, 731-734.

2. Bültmann, B., Wildfeuer, A., Schindelbeck, U., Kleihauer, E., Heimpel, H., Wigger, H. J. \& Haferkamp, O. (1982) Klin. Wochenschr. 60, 1289-1295.

3. Niethammer, D., Wildfeuer, A., Kleihauer, E. \& Haferkamp, O. (1975) Klin. Wochenschr. 53, 739-746.

4. Niethammer, D., Wildfeuer, A., Kleihauer, E. \& Haferkamp, O. (1975) Klin. Wochenschr. 53, 643-652.

5. Klebanoff, S. J. \& Clark, R. A. (1978) The Neutrophil, North Holland, Amsterdam.

6. Allen, R. C., Stjernholm, R. L. \& Steele, R. H. (1972) Biochem. Biophys. Res. Commun. 47, 679-684.

7. Roos, D. (1980) In: The Cell Biology of Inflammation (Weismann, G., ed.) Elsevier, Amsterdam pp. 337-386.

8. Babior, B. H., Kippens, R. S. \& Curnutte, J. T. (1973) J. Clin. Invest. 52, 741-744.

9. Babior, B. H. (1978) N. Engl. J. Med. 258, 659-668.

10. Rosen, H. \& Klebanoff, S. J. (1977) J. Biol. Chem. 252, 4803-4810.

11. Allen, R. C., Yevich, S. J., Orth, R. W. \& Steele, R. H. (1974) Biochem. Biophys. Res. Commun. 60, 909-917.

12. Allen, R. C. (1979) In: Frontiers in Biology 48, 197-233, North-Holland Amsterdam.

13. Allen, R. C. (1982) In: Biochemistry and Function of Phagocytes (Rossi, F. \& Patriarca, P., eds.) Plenum New York, pp. 411-422.

14. Steele, R. H., Allen, R. C. \& Reed, M. A. (1976) J. Reticuloendothel. Soc. 20, 25 a.

15. Ernst, M. (1980) Behring. Inst. Mitt. 65, 55-61.

16. Allen, R. C. \& Loose, L. D. (1976) Biochem. Biophys. Res. Commun. 69, 245-252.

17. Allen, R. C. (1981) In: Bioluminescence and Chemiluminescence (DeLuca, M. A. \& McElroy, W. D., eds.) Academic Press New York, pp. 63-73.

18. Roswell, D. f. \& White, E. H. (1978) Methods in Enzymology 58, 409-423.

19. Van Dyke, K. V., Trush, M., Wilson, M., Stealy, P. \& Miles, P. (1977) Microchem. J. 22, 463-474.

20. Stevens, P., Winston, D. J. \& Van Dyke, K. V. (1978) Infect. Immun. 22, 41-51.

21. Eschenbach, C. (1982) Klin. Wochenschr. 60, 357-364.

22. Barbour, A. G.; Allred, C. D. Solberg, C. O. \& Hill, H. R. (1980) J. Infect. Dis. 141, 14-26.

23. Allen, R. C. (1977) Infect. Immun. 15, 828-833.

24. Stevens, P. \& Welch, W. D. (1981) In: Bioluminescence and Chemiluminescence (De Luca, M. A. \& McElroy, W. D., eds.) pp. 75-80, Acad. Press, New York.
- 25. Wokalek, H., Kato, H., Schöpf, E., Eggert, H., Rietschel, E. T., Ernst, M. \& Fischer, H. (1980) Acta Dermatol. 6, $161-166$.

26. Kato, T., Wokalek, H., Schöpf, E., Eggert, H., Ernst, M., Rietschel, E. T. \& Fischer, H. (1981) Klin. Wochenschr. 59, 203-211.

27. Fischer, H., Kato, T., Wokalek, H., Ernst, M., Eggert, H. \& Rietschel, E. T. (1981) In: Bioluminescence and Chemiluminescence (DeLuca, M. A. \& McElroy, W. D., eds.) pp. 617-622, Acad. Press, New York.

28. Faden, H. \& Macrejewski, N. (1981) J. Reticuloendothel. Soc. 30, 219-226.

29. Heberer, M., Ernst, M., Harder, F. \& Fischer, H. (1981) Langenbecks Arch. Chir. 355, 643.

30. De Chatelet, L. R. \& Shirley, P. (1981) Clin. Chem. 27, 1739-1741.

31. Allen R. C. (1981) Proc. Int. Congr. Clin. Chem., Vienna, 1981.

32. Allen R. C. \& Pruitt, B. A. (1982) Arch. Surg. 117, 133-140.

33. Hjort, R., Jonsson, A. K. \& Vretblad, P. (1981) J. Immunol. Meth. 43, 95-101.

34. Nelson, R. D., Herron, M. J., Schmidke, J. R. \& Simmons, R. L. (1977) Infect. Immun. 17, 513-520.

35. Goldstein, J. M., Kaplan, H. B., Edelson, H. S. \& Weissmann, G. (1979) J. Biol. Chem. 254, 4040-4045.

36. Mills, E. J., Gerrard, J. M., Filipovich, D. \& James, D. (1978) J. Clin. Invest. $61,807-814$.

37. Webb, L. S., Keele, B. B. \& Johnston, R. B. (1974) Infect. Immun. 9, 1051-1056.

38. Lehmeyer, J. E., Snyderman, R. \& Johnston, R. B. (1979) Blood 54, 35-45.

39. Solberg, C. O., Allred, C. D. \& Hill, H. R. (1978) Acta Pathol. Microbiol. Scand. 86, 165-171.

40. Trush, M. A. \& Dyke, K. V. (1978) Pharmacology 16, 314.

41. Bjorkstein, B., Ray, C. \& Quie, P. G. (1976) Infect. Immun. $14,315$.

42. Redl, H., Lamache, H. \& Schlag, G. (1982) Personal communication.

43. Grogau, J. B. (1976) J. Trauma 16, 734-738.

44. Schmidt, K., Bruchelt, G., Kistler, D. \& Koslowski, L. (1983) Burns 10, 79-85.

45. Trush, M. A., Wilson, M. E. \& Van Dyke, K. (1979) Methods in Enzymology 57, 462-494.

46. Ewetz, L., Palmblad, J. \& Thore, A. (1982) Blut 43, $373-381$.

Prof. Dr. Dr. K. H. Schmidt

Klin.-chem. Laboratorium

der Chirurgischen Universitätsklinik

Calwer Straße 7

D-7400 Tübingen 
,

. 